\title{
Enhanced Impact Properties of Hybrid Composites Reinforced by Carbon Fiber and Polyimide Fiber
}

\author{
Boyao Wang ${ }^{1,+}$, Bin $\mathrm{He}^{1,+}{ }^{\dagger}$ Zhanwen Wang ${ }^{1}$, Shengli Qi ${ }^{1}$, Daijun Zhang ${ }^{2}$, Guofeng Tian ${ }^{1, *}$ and Dezhen Wu ${ }^{1, *}$ \\ 1 State Key Laboratory of Chemical Resource Engineering, Beijing University of Chemical Technology, \\ Beijing 100029, China; 2018210146@buct.edu.cn (B.W.); hebin90s@163.com (B.H.); \\ 13011142122@163.com (Z.W.); qisl@mail.buct.edu.cn (S.Q.) \\ 2 National Key Laboratory of Advanced Composite Materials, Aero Engine Corporation of China Beijing \\ Institute of Aeronautical Materials, Beijing 100095, China; 15810534483@139.com \\ * Correspondence: tiangf@mail.buct.edu.cn (G.T.); wdz@mail.buct.edu.cn (D.W.) \\ $\dagger$ These authors contributed equally to this work.
}

Citation: Wang, B.; He, B.; Wang, Z.; Qi, S.; Zhang, D.; Tian, G.; Wu, D.

Enhanced Impact Properties of

Hybrid Composites Reinforced by Carbon Fiber and Polyimide Fiber. Polymers 2021, 13, 2599. https:// doi.org/10.3390/polym13162599

Academic Editors: Bon-Cheol Ku and Michael Nase

Received: 29 June 2021

Accepted: 2 August 2021

Published: 5 August 2021

Publisher's Note: MDPI stays neutral with regard to jurisdictional claims in published maps and institutional affiliations.

Copyright: () 2021 by the authors. Licensee MDPI, Basel, Switzerland. This article is an open access article distributed under the terms and conditions of the Creative Commons Attribution (CC BY) license (https:// creativecommons.org/licenses/by/ $4.0 /)$.

\begin{abstract}
A series of hybrid fiber-reinforced composites were prepared with polyimide fiber and carbon fiber as the reinforcement and epoxy resin as the matrix. The influence of stacking sequence on the Charpy impact and flexural properties of the composites as well as the failure modes were studied. The results showed that hybrid fiber-reinforced composites yielded nearly $50 \%$ increment in Charpy impact strength compared with the ones reinforced by carbon fiber. The flexural performance was significantly improved compared with those reinforced solely by polyimide fibers and was greatly affected by the stacking sequence. The specimens with compressive sides distributed with carbon fiber possessed higher flexural strength, while those holding a sandwich-like structure with carbon fiber filling between the outer layers displayed a higher flexural modulus.
\end{abstract}

Keywords: polymer-matrix composites (PMCs); hybrid; Charpy impact strength; polyimide fiber

\section{Introduction}

A typical representative of advanced composites, resin-based composites reinforced by carbon fiber with features such as being light weight and having high strength and modulus have found broad applications in the fields of upmarket sports equipment and aerospace equipment [1-3]. However, the high rigidity of carbon fiber incurs brittleness and poor toughness [4-7], which makes the composites prepared show relatively low impact resistance. Hybrid-fiber reinforcement can take full advantage of the performance superiorities of two or more kinds of fibers to make up for the deficiencies of a single reinforcement pattern in certain properties [8-10]. Mixing carbon fiber with ones possessing high toughness and ductility has been proposed as another effective way to improve the toughness of original composites [11,12].

Polyimide (PI) fiber with high strength and high modulus is a kind of high-performance organic fiber that has newly emerged in recent years. It has excellent mechanical properties, tolerance to high and low temperatures, environmental resistance, little moisture absorption, low dielectric, and high insulation [13-21]. PI fiber is composed of amorphous polymer with highly oriented molecular chains. When impacted by external force, it can absorb and dissipate energy through chain movement; the timely conversion of kinetic energy into thermal energy required by the thermal motion of molecular chains endows the fiber with excellent toughness. Our previous research indicated PI fiber underwent plastic deformation during quasi-static tension, while fibrillation occurred during high-strain-rate tension, both of which were conducive to energy absorption and thereby toughness enhancement [22]. Therefore, we decided to explore whether PI fibers and carbon fibers could be simultaneously adopted to prepare hybrid fiber-reinforced composites (HFRP), so as to make full use of the high toughness of PI fiber to balance the stiffness and toughness 
of carbon fiber-reinforced composites (CFRP), and in the meantime, improve the impact resistance of composites. In addition, PI fiber has a density as low as $1.44 \mathrm{~g} / \mathrm{cm}^{3}$, which is about $20 \%$ lower than that of carbon fiber, so it could also play a role in structural weight reduction. HFRP is expected to be used as an impact-resistant material in automotive, aerospace, and other fields.

Herein, with S35 PI fiber fabric and T700 carbon fiber fabric used as reinforcements and epoxy resin as the matrix, a series of HFRP laminates were prepared by solution-based prepreg combined via the hot molding method. The effects of stacking sequence on the impact and flexural properties of the composites were systematically studied, and the failure mode of the specimens was observed and analyzed in detail. It is expected that our research can provide new design ideas for stacking sequence and material selection schemes for impact-resistant composites [23-25].

\section{Experiments}

\subsection{Materials}

Carbon fiber fabric (T700-12K) with an areal density of $200 \mathrm{~g} / \mathrm{m}^{2}$ was commercially available. The PI fiber (S35, Jiangsu Shino New Materials \& Technology Co., Ltd, Changzhou, China) fabric had an areal density of $200 \mathrm{~g} / \mathrm{m}^{2}$. Epoxy resin $(4,5-$ epoxycyclohexane-1,2-dicarboxylic acid diglycidyl ester, TDE-85) was obtained from Tianjin Jingdong Chemical Composites Co., Ltd, Tianjin, China. The curing agent (3,3'-diethyl4,4'-diaminodiphenylmethane, DEDDM) was produced by Jiangyin Huifeng Electronic Materials Co., Ltd, Wuxi, China. The acetone was produced by Beijing Chemical Plant, Beijing, China. Mechanical parameters of the raw fibers are listed in Table 1.

Table 1. Constituent materials and selected properties.

\begin{tabular}{ccccc}
\hline Material & $\begin{array}{c}\text { Tensile } \\
\text { Strength (MPa) }\end{array}$ & $\begin{array}{c}\text { Tensile } \\
\text { Modulus (GPa) }\end{array}$ & Elongation (\%) & Density (g/cm ${ }^{\mathbf{3}}$ ) \\
\hline Carbon fiber & 4900 & 230 & 2.1 & 1.80 \\
(T700-12K) & 3500 & 120 & $>3.0$ & 1.44 \\
\hline PI fiber (S35) & 350 & \\
\hline
\end{tabular}

\subsection{Preparation}

TDE-85 and DEDDM were mixed at a mass ratio of 0.65:0.35, and then added to an appropriate amount of acetone to prepare the resin solution. The fabric was cut into the required sizes to fabricate the prepreg through a solution-based method. After hot-press curing, a series of fabric-reinforced composite laminates were obtained. The curing procedure was $125^{\circ} \mathrm{C} / 2 \mathrm{~h}+165^{\circ} \mathrm{C} / 3 \mathrm{~h}+185^{\circ} \mathrm{C} / 3 \mathrm{~h}$, which was in accordance with previous work [26], and the curing pressure was $3 \mathrm{MPa}$. In this work, the hybrid ratio was defined as the mass percentage of carbon fiber in the total fiber. The specific fabrication details under each laminate code are described in detail in Table 2 and Scheme 1. H1 stands for the interlaminar hybrid of alternating stacking structure. $\mathrm{H} 2$ and $\mathrm{H} 3$ represent asymmetric stacking structure. $\mathrm{H} 4$ and $\mathrm{H} 5$ have sandwich-like structures, with the outer layers being PI fiber and carbon fiber, respectively. 
Table 2. Stacking sequence of hybrid composites.

\begin{tabular}{|c|c|c|c|}
\hline Laminate Code & $\begin{array}{l}\text { Ply Number Ratio } \\
\text { (Carbon/Polyimide) }\end{array}$ & Stacking Sequence & Hybrid Ratio (\%) \\
\hline PFRP & $0 / 12$ & 000000000000 & 0 \\
\hline CFRP & $12 / 0$ & 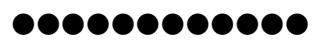 & 100 \\
\hline H1 & $6 / 6$ & $\bigcirc \bullet \bigcirc \bigcirc \bullet \bullet \bigcirc \bigcirc \bullet \bigcirc$ & 50 \\
\hline $\mathrm{H} 2$ & $6 / 6$ & 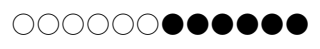 & 50 \\
\hline H3 & $6 / 6$ & 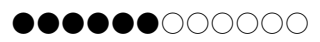 & 50 \\
\hline $\mathrm{H} 4$ & $6 / 6$ & 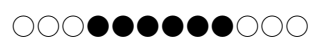 & 50 \\
\hline H5 & $6 / 6$ & 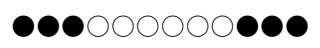 & 50 \\
\hline
\end{tabular}

Note: $\bigcirc$ represents polyimide fiber, $\bullet$ represents carbon fiber.

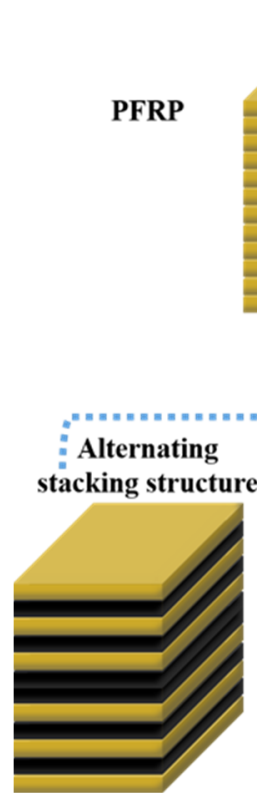

H1
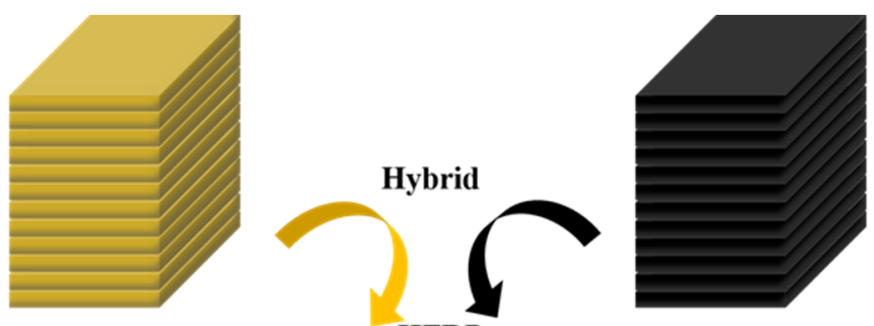

CFRP

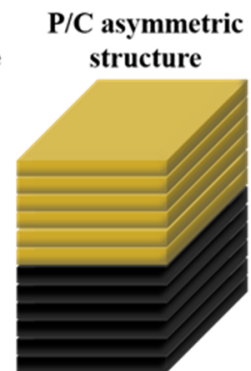

$\mathrm{H} 2$

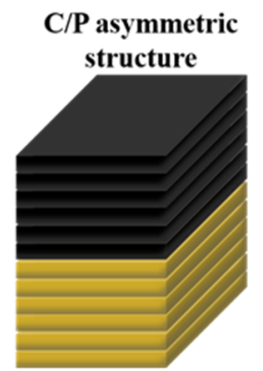

H3

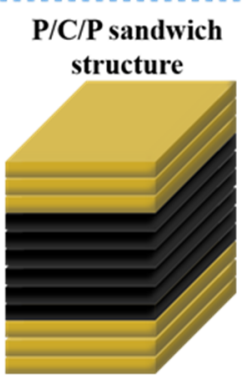

H4
C/P/C sandwich

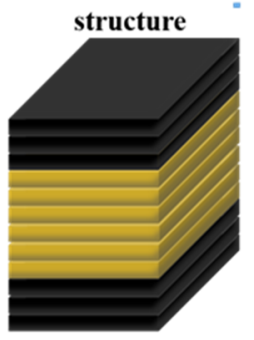

H5

Scheme 1. Stacking sequence of HFRP.

\subsection{Characterization}

The mechanical testing standards for composite laminates in this work are detailed in Table 3. A HIT 25P pendulum impact testing machine was used to evaluate Charpy impact properties. The impact was directed vertically through the layers, and the spanto-depth ratio was 20. Flexural properties were examined on an Instron 5966 electronic universal material testing machine. Three-point bending was applied for the bending test. The span-to-depth ratio was 32 for the bending specimens. There were five specimens in each group, and the average values were reported. The macroscopic appearance was recorded with a digital camera and an optical microscope.

Table 3. Mechanical property measurements.

\begin{tabular}{|c|c|c|c|}
\hline Tests & Standard & $\begin{array}{c}\text { Specimen } \\
\text { Dimensions } \\
(\mathrm{mm} \times \mathbf{m m} \times \mathbf{m m})\end{array}$ & $\begin{array}{l}\text { Loading Rate } \\
\text { (mm/min) }\end{array}$ \\
\hline Impact test & GB/T 1043.1-2008 & $75 \times 10 \times 2$ & / \\
\hline Three-point bending test & ASTM D7264 & $80 \times 13 \times 2$ & 2 \\
\hline
\end{tabular}




\section{Results and Discussion}

\subsection{Charpy Impact Properties}

Charpy impact strengths of the composites are summarized in Figure 1, which reveals an order of $\mathrm{H} 1<\mathrm{CFRP}<\mathrm{PFRP}<\mathrm{H} 4<\mathrm{H} 5$. The error bars represent standard deviation. PFRP demonstrated a higher impact strength than that of CFRP $\left(263.8 \mathrm{~kJ} / \mathrm{m}^{2}\right.$ versus $217.2 \mathrm{~kJ} / \mathrm{m}^{2}$ ), indicative of its better impact resistance. The impact strength of HFRP was strongly related to the stacking sequence. Specifically, the sandwich structure was more conducive to the improvement of impact strength, with $280.6 \mathrm{~kJ} / \mathrm{m}^{2}$ and $324.3 \mathrm{~kJ} / \mathrm{m}^{2}$ obtained by $\mathrm{H} 4$ and $\mathrm{H} 5$, respectively, which are much higher values than those of PFRP and CFRP. H5 achieved the highest impact strength and an increment of approximately 50\% compared with CFRP, exhibiting better impact resistance. The remarkable enhancement for $\mathrm{H} 5$ might be explained as follows: the carbon fiber outer layer was beneficial to the rapid diffusion of stress waves because of its high modulus, and PI fiber in the core layer was favorable for the absorption of impact energy due to its high elongation at breaking point.

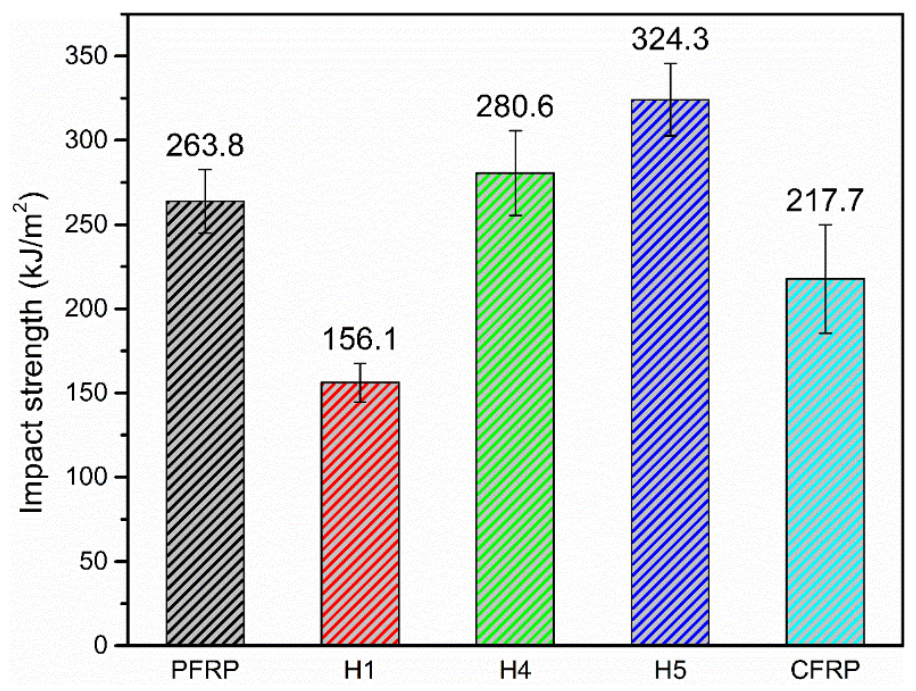

Figure 1. Impact strength of the composites.

The morphology of the surfaces of the composites after the Charpy impact test was further characterized by optical microscopy (Figure 2). Delamination was found in the PFRP specimen; the PI fiber layer on the compressive side yielded and showed kinking failure, while that on the tensile side underwent tensile failure with some fiber broken and pulled out (Figure 2a). On the other hand, overall fracture with a through-thickness break could be clearly observed for CFRP, and the broken fiber presented sharp brittle fractures (Figure $2 b$ ). 

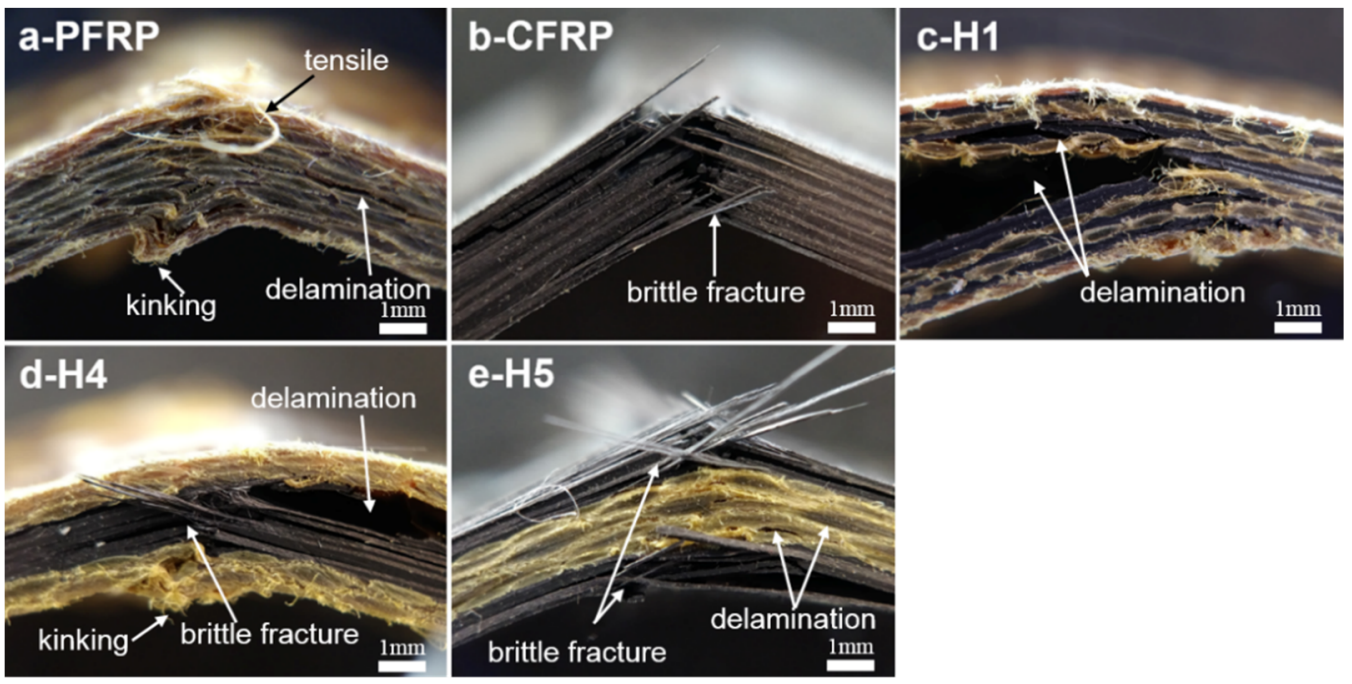

Figure 2. Morphology of surfaces of composite specimens after impact test: (a) PFRP, (b) CFRP, (c) H1, (d) H4, and (e) H5.

Figure 2c-e suggest that none of the HFRPs underwent complete fracture, and all the specimens maintained good integrity. Delamination occurred in all three cases, although the delamination situation was different in each case. It took place at the interface of PI fiber/carbon fiber in the alternating stacking structure (H1). For the sandwich-like H4, the inner carbon fiber layer suffered brittle fracture; meanwhile, delamination occurred at the PI fiber/carbon fiber interface on the tensile side, and kinking failure appeared on the compressive side. $\mathrm{H} 5$ also held a sandwich structure but in an inverse pattern; the carbon fiber outer layer failed on both the tensile side and compressive side similarly to the CFRP specimen, while multiple delamination occurred in the inner PI fiber layer.

\subsection{Flexural Properties}

Flexural stress-strain curves of the composite specimens are plotted in Figure 3a. The curves represent the average value of the samples. The stiffness of carbon fibers imparted a good linearity to the CFRP curve, which rose steeply at first and dropped instantly upon reaching the critical stress, indicative of high flexural strength, high flexural modulus, and low failure strain of CFRP. As for PFRP, the ductility of PI fibers resulted in a nonlinear curve. Therefore, PFRP possessed low flexural strength, low flexural modulus, but a failure strain over $6.5 \%$, which is much higher than that of CFRP and thus shows excellent toughness.

The flexural modulus of PFRP and CFRP was 30.0 and $76.1 \mathrm{GPa}$, respectively, while that of HFRP (H1-H5) was in between these values (Figure 3b). The order of flexural modulus of HFRP followed $\mathrm{H} 5>\mathrm{H} 3>\mathrm{H} 2>\mathrm{H} 1>\mathrm{H} 4$. The partial replacement of PI fibers with carbon fibers could enhance the flexural modulus to various degrees as the layer sequence varied. With the outer layer consisting of carbon fiber, the sandwich-like H5 showed the highest flexural modulus of $70.1 \mathrm{GPa}$, which reached $92 \%$ of that of CFRP.

The flexural strengths of the composites are compared in Figure 3c. The flexural strength of PFRP and CFRP was 386.1 and $1364.5 \mathrm{MPa}$, respectively, and that of HFRP $(\mathrm{H} 1-\mathrm{H} 5)$ fell in between these values. The introduction of carbon fiber caused a marked improvement, which also largely depended on the stacking sequence. Carbon fiber being in the outer layer (i.e., H5) was more beneficial than being in the core layer (i.e., H4). Replacing PI fiber with carbon fiber in the outer layer of the compressive side to withstand more compressive stress could significantly improve the flexural strength of HFRP. Among all the HFRP specimens, H5 maintained excellent flexural strength of approximately $1004 \mathrm{MPa}$, which was 2.6 times that of PFRP and 75\% of CFRP. 

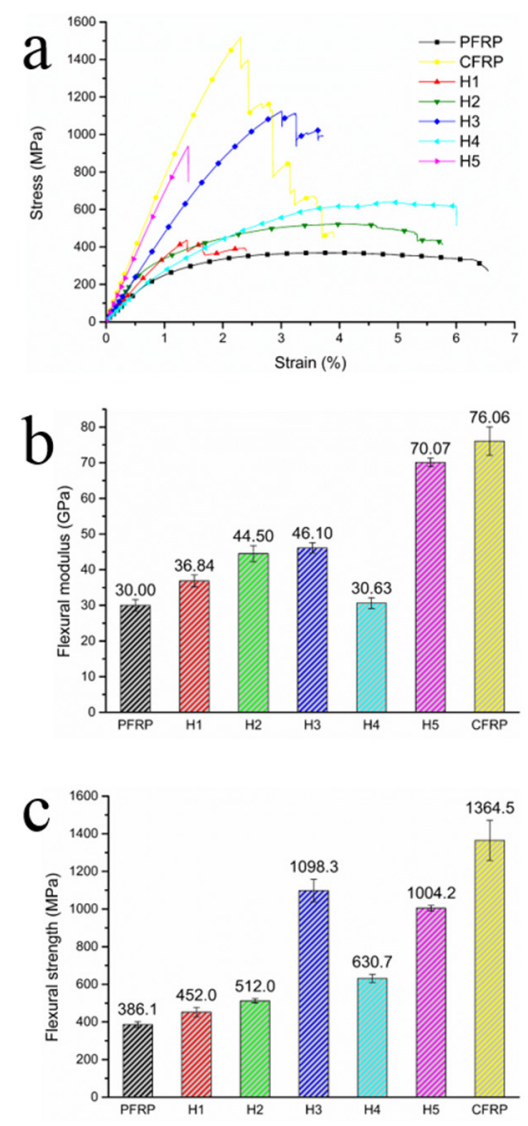

Figure 3. Flexural properties of the composites: (a) flexural stress-strain curves, (b) flexural modulus, and (c) flexural strength.

According to the morphology of the surface in Figure 4, PFRP showed kinking failure on the compressive side but no fracture, which can be attributed to the toughness of PI fiber. CFRP underwent both tensile and compressive failure, and crack propagation led to multiple delamination sites on the compressive side. The compressive side of $\mathrm{H} 2$ had no crack propagation due to the toughness of PI fiber, for which $\mathrm{H} 2$ had a large flexural failure strain. As for $\mathrm{H} 3$, cracks on the compressive side propagated from the carbon fiber layer to the inner PI fiber layer, triggering delamination similar to CFRP. With both outer layers being PI fiber, $\mathrm{H} 4$ showed large deformations on the compressive side along with obvious failure on the tensile side, demonstrated by delamination and fabric buckling. Cracks occurred in the carbon fiber layer on the compressive side of $\mathrm{H} 5$ and propagated throughout the entire layer, but it could not pass through the PI fiber layer. In general, the continuous carbon fiber layer was prone to crack propagation, while the PI fiber layer could block crack propagation due to its excellent toughness. When set in a suitable position, the PI fiber layer could afford greater flexural strain. By delicate design of the stacking sequences of carbon fiber and PI fiber, HFRP with good flexural properties that can meet the needs of practical applications can be obtained. 

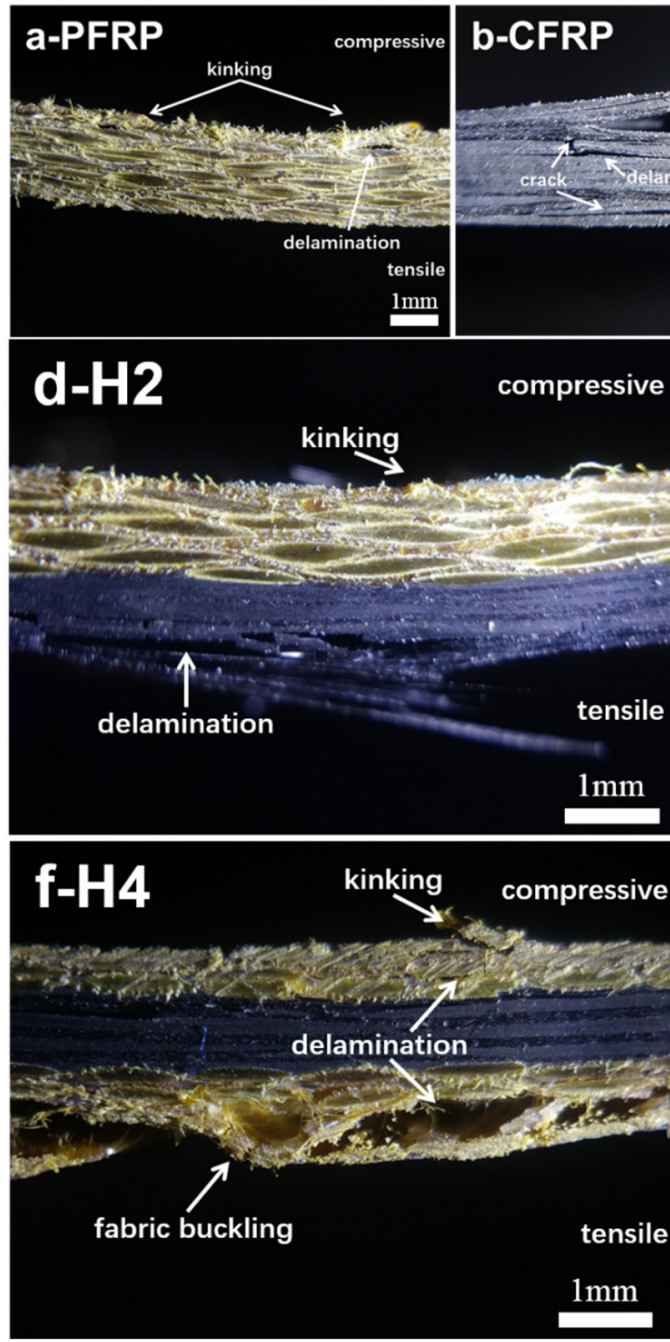

Figure 4. Morphology of the surface of failed composite laminates under flexural loading: (a) PFRP, (b) CFRP, (c) H1, (d) H2, (e) H3, (f) H4, (g) H5.

\section{Conclusions}

PI fiber fabric and carbon fiber fabric were used as reinforcements and epoxy resin was used as the matrix to prepare a series of interlayer hybrid composites. The effects of stacking sequence on the basic mechanical properties and failure modes of the composites have been discussed. Experimental results showed that stacking sequence could make a difference to the Charpy impact properties and flexural properties of HFRP. The Charpy impact strength of sandwich-like structures with the outer layers being carbon fiber (H5) was nearly $50 \%$ higher than that of CFRP, and its flexural strength also maintained $75 \%$ of that of CFRP, which demonstrates excellent structural strength. Further, carbon fiber on the compressive side was very helpful for the improvement of flexural strength and modulus.

In conclusion, with reasonable structural design, sandwich-like structures could improve the impact resistance of hybrid composites to a large extent, and maintain the flexural performance of the hybrid composites.

Author Contributions: Conceptualization, B.W., B.H. and G.T.; Data curation, S.Q.; Formal analysis, Z.W.; Investigation, B.W. and B.H.; Methodology, B.W. and B.H.; Project administration, D.Z. and G.T.; Supervision, D.W.; Writing—original draft, B.W. and B.H.; Writing—review \& editing, G.T. and D.W. All authors have read and agreed to the published version of the manuscript. 
Funding: This research was funded by the Science and Technology on Transient Impact Laboratory Foundation (Project no. 6142606183208) and the Fundamental Research Funds for the Central Universities (XK1802-2).

Institutional Review Board Statement: Not applicable.

Informed Consent Statement: Not applicable.

Data Availability Statement: The data presented in this study are available on request from the corresponding author.

Conflicts of Interest: The authors declare no conflict of interest.

\section{References}

1. Sugiyama, K.; Matsuzaki, R.; Ueda, M.; Todoroki, A.; Hirano, Y. 3D printing of composite sandwich structures using continuous carbon fiber and fiber tension. Compos. Part A Appl. Sci. Manuf. 2018, 113, 114-121. [CrossRef]

2. Duongthipthewa, A.; Su, Y.; Zhou, L. Electrical conductivity and mechanical property improvement by low-temperature carbon nanotube growth on carbon fiber fabric with nanofiller incorporation. Compos. Part B Eng. 2020, 182, 107581. [CrossRef]

3. Yao, S.-S.; Jin, F.-L.; Rhee, K.Y.; Hui, D.; Park, S.-J. Recent advances in carbon-fiber-reinforced thermoplastic composites: A review. Compos. Part B Eng. 2018, 142, 241-250. [CrossRef]

4. Hassan, E.A.M.; Yang, L.; Elagib, T.H.H.; Ge, D.; Lv, X.; Zhou, J.; Yu, M.; Zhu, S. Synergistic effect of hydrogen bonding and pi-pi stacking in interface of CF/PEEK composites. Compos. Part B Eng. 2019, 171, 70-77. [CrossRef]

5. Farooq, U.J.; Teuwen, J.; Dransfeld, C. Toughening of Epoxy Systems with Interpenetrating Polymer Network (IPN): A Review. Polymers 2020, 12, 1908. [CrossRef] [PubMed]

6. Wu, Z.; Yi, X.-S.; Wilkinson, A. Interlaminar fracture toughness of carbon fibre/RTM6-2 composites toughened with thermoplasticcoated fabric reinforcement. Compos. Part B Eng. 2017, 130, 192-199. [CrossRef]

7. Nash, N.H.; Young, T.M.; Stanley, W.F. The influence of a thermoplastic toughening interlayer and hydrothermal conditioning on the Mode-II interlaminar fracture toughness of Carbon/Benzoxazine composites. Compos. Part A Appl. Sci. Manuf. 2016, 81, 111-120. [CrossRef]

8. Jesthi, D.K.; Nayak, R.K. Improvement of mechanical properties of hybrid composites through interply rearrangement of glass and carbon woven fabrics for marine application. Compos. Part B Eng. 2019, 168, 467-475. [CrossRef]

9. Chen, D.; Luo, Q.; Meng, M.; Li, Q.; Sun, G. Low velocity impact behavior of interlayer hybrid composite laminates with carbon/glass/basalt fibres. Compos. Part B Eng. 2019, 176, 107191. [CrossRef]

10. Bunea, M.; Circiumaru, A.; Buciumeanu, M.; Birsan, I.G.; Silva, F.S. Low velocity impact response of fabric reinforced hybrid composites with stratified filled epoxy matrix. Compos. Sci. Technol. 2019, 169, 242-248. [CrossRef]

11. Li, G.; Zhang, C.; Wang, Y.; Li, P.; Yu, Y.; Jia, X.; Liu, H.; Yang, X.; Xue, Z.; Ryu, S. Interface correlation and toughness matching of phosphoric acid functionalized Kevlar fiber and epoxy matrix for filament winding composites. Compos. Sci. Technol. 2008, 68, 3208-3214. [CrossRef]

12. Li, W.; Liu, X.; Feng, M.; Yang, J. Bamboo-like ultra-high molecular weight polyethylene fibers and their epoxy composites. Compos. Sci. Technol. 2019, 182, 107716. [CrossRef]

13. Chang, J.; Ge, Q.; Zhang, M.; Liu, W.; Cao, L.; Niu, H.; Suib, G.; Wu, D. Effect of pre-imidization on the structures and properties of polyimide fibers. RSC Adv. 2015, 5, 69555-69566. [CrossRef]

14. Zhang, M.; Niu, H.; Chang, J.; Ge, Q.; Cao, L.; Wu, D. High-performance fibers based on copolyimides containing benzimidazole and ether moieties: Molecular packing, morphology, hydrogen-bonding interactions and properties. Polym. Eng. Sci. 2015, 55, 2615-2625. [CrossRef]

15. Zhang, M.; Niu, H.; Lin, Z.; Qi, S.; Chang, J.; Ge, Q.; Wu, D. Preparation of High Performance Copolyimide Fibers via Increasing Draw Ratios. Macromol. Mater. Eng. 2015, 300, 1096-1107. [CrossRef]

16. Sun, M.; Chang, J.; Tian, G.; Niu, H.; Wu, D. Preparation of high-performance polyimide fibers containing benzimidazole and benzoxazole units. J. Mater. Sci. 2016, 51, 2830-2840. [CrossRef]

17. Zhang, M.; Liu, W.; Niu, H.; Wu, D. Structure-property relationship of carbon fibers derived from polyimide/polyacrylonitrile blends. High Perform. Polym. 2019, 31, 168-177. [CrossRef]

18. Chang, J.; Niu, H.; He, M.; Sun, M.; Wu, D. Structure-property relationship of polyimide fibers containing ether groups. J. Appl. Polym. Sci. 2015, 132, 42474. [CrossRef]

19. Chang, J.; Niu, H.; Zhang, M.; Ge, Q.; Li, Y.; Wu, D. Structures and properties of polyimide fibers containing ether units. J. Mater. Sci. 2015, 50, 4104-4114. [CrossRef]

20. Zhuo, H.; Li, S.; Han, E.; Zhang, D.; Liu, G.; Tian, G.; Bao, J.; Wu, D. Mechanical properties and failure mechanism of high strength and high modulus polyimide fiber reinforced epoxy composites. Acta Mater. Compos. Sin. 2019, 36, 2101-2109.

21. Li, S.; Zhuo, H.; Han, E.; Zhang, D.; Liu, G.; Tian, G.; Bao, J.; Wu, D. Preparation and properties of high strength and high modulus polyimide fiber/modified cyanate resin composites. Acta Mater. Compos. Sin. 2020, 37, 42-49.

22. Wang, B.; Zhang, M.; Han, E.; Tian, G.; Wang, G.; Wu, D. Mechanical behavior of polyimide filament tows under high strain rate tension. High Perform. Polym. 2020, 32, 842-848. [CrossRef] 
23. Shi, H.; Ching, W.; Ruo, Y.; Qi, L.; Ting, L.; Yue, S.; Lin, J.-H. Investigation on structure and impact-resistance property of polyurethane foam filled three-dimensional fabric reinforced sandwich flexible composites. Compos. Part B Eng. 2017, 131, 43-49.

24. Priyanka, A.; Dixit, A.; Mali, H.S. High-Strength Hybrid Textile Composites with Carbon, Kevlar, and E-Glass Fibers for Impact-Resistant Structures. A Review. Mech. Compos. Mater. 2017, 53, 685-704. [CrossRef]

25. Akonda, M.H.; Kandola, B.K.; Horrocks, A.R.; Myler, P. The effect of fibrous reinforcement on optical and impact performance of fibre-reinforced transparent glass composites. J. Mater. Sci. 2014, 49, 1903-1913. [CrossRef]

26. He, B.; Wang, B.; Wang, Z.; Qi, S.; Tian, G.; Wu, D. Mechanical properties of hybrid composites reinforced by carbon fiber and high-strength and high-modulus polyimide fiber. Polymer 2020, 204, 122830. [CrossRef] 